\title{
Autonomic Computing - Panacea or Poppycock?
}

EASe 2005 Birds of a Feather Session

\author{
Roy Sterritt \\ School of Computing and Mathematics \\ Faculty of Engineering \\ University of Ulster \\ Northern Ireland \\ r.sterritt@ulster.ac.uk
}

\author{
Mike Hinchey \\ NASA Goddard Space Flight Center \\ Software Engineering Laboratory \\ Greenbelt, MD 20771 \\ USA \\ michael.g.hinchey@nasa.gov
}

\section{Definitions ${ }^{\dagger}$}

au·to·nom·ic (àwtə nómmik)

adj.

1. Physiology.

a. Of, relating to, or controlled by the autonomic nervous system.

b. Occurring involuntarily; automatic: an autonomic reflex.

2. Resulting from internal stimuli; spontaneous.

au·ton·o·mic·i-ty (àwto nóm i síttee)

$n$.

1. The state of being autonomic.

au·ton-o·mous (aw tónnəməs)

adj.

1. Not controlled by others or by outside forces; independent: an autonomous judiciary; an autonomous division of a corporate conglomerate.

2. Independent in mind or judgment; self-directed.

3.

a. Independent of the laws of another state or government; self-governing.

b. Of or relating to a self-governing entity: an autonomous legislature.

c. Self-governing with respect to local or internal affairs: an autonomous region of a country.

4. Autonomic.

[From Greek autonomos : auto-, auto- + nomos, law]

${ }^{+}$Adapted from American Heritage Dictionary of the English Language, $4^{\text {th }}$ edition. pan-a-ce`a (pànnə see ə)

$n$.

A remedy for all diseases, evils, or difficulties; a cure-all.

[Latin panacea, from Greek panakeia, from panakes, allhealing : pan-, pan-+ akos, cure.]

pop-py-cock (póppee kòk)

$n$.

Senseless talk; nonsense.

[Dutch dialectal pappekak : pap, pap (from Middle Dutch pappe, perhaps from Latin pappa, food) + kak, dung (from kakken, to defecate, from Middle Dutch kacken, from Latin cacare.]

\section{A Brief History of Autonomicity}

Autonomic Computing arose out of a need for a means to cope with rapidly growing complexity of integrating, managing, and operating computer-based systems as well as a need to reduce the total cost of ownership of today's systems.

Autonomic Computing (AC) as a discipline was proposed by IBM in 2001, with the vision to develop self-managing systems [1]. As the name implies, the influence for the new paradigm is the human body's autonomic system, which regulates vital bodily functions such as the control of heart rate, the body's temperature and blood flow-all without conscious effort.

The vision is to create selfware through self-* properties. The initial set of properties, in terms of objectives, were self-configuring, self-healing, selfoptimizing and self-protecting, along with attributes of self-awareness, self-monitoring and self-adjusting. This self-* list has grown: self-anticipating, self-critical, selfdefining, self-destructing, self-diagnosis, self-governing, 
self-organized, self-reflecting, and self-simulation, for instance [2][3].

\section{Some EASe Success Stories}

Although the Autonomic Computing initiative itself is still very much in its infancy, there have been, nevertheless, a number of success stories in developing autonomic systems reported at EASe 2004 and EASe 2005 , along with the identification of a number of challenges:

- Rouff et al. [4] [8] describe a forthcoming NASA mission which is a concept for future missions involving swarm technology, which will necessitate autonomic behavior, and which highlights great challenges for verification of this class of systems.

- Sterritt et al. [5] highlight the importance of a reflex-healing dual strategy to facilitate the addition of autonomic capabilities to the telecommunications fault management architecture.

- Nichols and Bapty [6] describe an adaptive image processing environment that allows solutions of complex image processing problems to be built and executed rapidly on a number of hardware architectures.

- Shetty et al. [7] describe a language to define behaviors for the $\mathrm{BTeV}$ trigger system, which is being used as a model for tools for defining fault behavior and automatically generating software.

- Truszkowski et al. [9] describe the autonomic properties of two NASA legacy multi-agent systems, namely Agent Concept Testbed (ACT) and the Lights-Out Ground Operations System (LOGOS).

- Gracanin et al. [10] describe the use of a modelbased architecture for the development of autonomic systems, using the COUGAAR architecture as a platform.

- Caseau [11] describes a set of adaptive methods and rules for routing messages in an Enterprise Application Environment, which yields a form of autonomic behavior.

- Sterritt and Chung [12] describe a proof-ofconcept self-healing tool for the personal computing environment, which incorporates a pulse monitor and vital signs health monitor.

- The correspondence between elements of control systems and those of autonomic systems is identified by Diao et al. [13], who propose a Deployable Testbed for Autonomic Computing
(DATC), in order to benefit from the methodologies of control theory, and simultaneously address the challenges of applying control theory to computing systems.

- Randles et al. [14] highlight the need for a metaframework for self-governance, in order to achieve large-scale autonomicity.

- Wang and Mathur [15] present an interceptorbased approach for constraint-violation detection, for which monitor code can be generated automatically from XML-based constraint specifications.

- The potential benefit of using well-established systems engineering concepts and techniques in the development of complex systems is evaluated by Bustard et al. [16], with particular reference to two existing well-established methodologies.

- An autonomic system that supports transparent stream synchronization in multimedia streaming applications, with necessary components installed on the fly, is described by Friedland and Pauls [17].

- An autonomic system integration platform where holistic design models capture system structure and target system resources and autonomic behavior, is proposed by Shetty et al. [18].

- Rash et al. [19] describe a tool to support fully formal requirements-based programming, and describe its application to a system that exhibits autonomic properties.

- A comprehensive prototype autonomic system, in which self-optimizing agents provide a selfhealing layer with ability to discover, diagnose, and reaci to discontinuities in real-time processing, is discussed by Messie et al. [20].

- Sterritt and Hinchey [21] describe apoptosis and self-destruction, the "ultimate" self-protection mechanism in autonomic systems, as applied to space missions.

- PACT - Personal Autonomic Computing Tools describes efforts, in terms of prototypes, to increase the degree of autonomicity in today's personal systems [22].

- Baldassari et al. [23] describe an experimental cluster management system, which, although small, demonstrates a decrease in overhead as the cluster size grows.

- A theoretical protocol for autonomic distribution of services in a P2P environment is presented by Saffre and Blok [24], who aim to demonstrate that distribution that meets the requirements of the community can be achieved without centralized resource management. 


\section{Challenges for the Future}

\subsection{Learning from Past Experience}

Several promising fields of engineering and computer science have suffered badly from unwarranted claims, exaggeration of benefits, or extrapolation of minor results to make claims of finding the "holy grail."

Formal methods for system specification and design, for example, have failed to live up to the exaggerated claims that were made about their benefits. Unfounded claims included that formal methods would result in fully correct computer systems [25]. What protagonists failed to consider is that they would result in systems that were correct with respect to their specifications. If specifications were flawed then too would be the resulting systems. Of course, formal methods offer opportunities to uncover errors in specifications, resulting in high quality software systems that are often cheaper to develop since errors are uncovered early [26][27]. Notwithstanding these benefits, formal methods are often considered to have failed to meet up to the claims made for them. Unfortunately, these claims were unreasonable.

Neural networks, evolutionary programming, and fuzzy logic have all suffered similar fates. Despite useful results and contributions to the advancement of Computing, early claims that these approaches could offer some form of "magic wand" that would solve a multitude of problems, or even all problems, simply could not be lived up to. The result is a cynical view by the public, funding agencies, and even researchers themselves, as to the benefits of these disciplines.

A similar situation arose with the field of Artificial Intelligence itself. In the 1950 s and $1960 \mathrm{~s}$, protagonists claimed (falsely) to have invented computers that could think. In reality, all they had accomplished at the time was a computer program that could solve a single simple problem. The techniques that were produced were well worth pursuing further, but were far from embodying the elusive "machines that think."

Herb Simon, in his memoirs [28], recounts that his students claim he told them in class one Monday morning that over the weekend he and Alan Newell had invented a computer program that could think. Simon admits that to have made such a claim would be ludicrous, and didn't recall doing so; he concedes, however, that there were so many "witnesses" that he must have made such a claim.

Such outlandish claims were used by the opponents of Artificial Intelligence to "demonstrate" that computers would never be able to do the sorts of things that the proponents of $\mathrm{AI}$ were claiming [29], and indeed had a major role in influencing the findings of the 1973
Lighthill Report, which all but ended funding for AI research in the UK at the time.

\subsection{A Balanced View}

We believe that Autonomic Computing has much to offer in the advancement of complex computer-based systems.

We expect to see many additional self-properties being added to the portfolio of behaviors expected of an autonomic computing system. We anticipate many new biologically-inspired metaphors being developed and incorporated into future autonomic systems.

We believe, however, that the community needs to keep a balanced view. While we see autonomic computing and the autonomic metaphor as being a major step forward and a useful contribution to the future of Computing, we must be careful not to make unfounded claims for it, nor to have unreasonable expectations of it.

\subsection{Panacea of Poppycock?}

We certainly don't see Autonomic Computing as "poppycock", but we realize we're probably preaching to the choir on that.

Nor, however, do we see it as a panacea. In fact, we do not believe that any such panacea exists nor could exist. The development of computer-based systems involves the complex interactions between a number of stakeholders, meeting a variety of desiderata such as cost, lead-time, functional and non-functional requirements, development standards both self-imposed (e.g., quality standards, or for certification purposes) and mandated (by government and other bodies), ease of use, maintainability, etc.

The Autonomic Computing community is performing some excellent work, both research and applied. We believe that many of the results currently being produced will become standard practice in a variety of domains in the future. This is particularly true in situations where computer systems must be autonomous, either because they are required to perform tasks that are not possible for humans to perform (e.g., deep space exploration), or tasks that require decisions to be made so quickly that waiting for human intervention is just not feasible. We believe that these classes of autonomous systems will exhibit autonomic properties more and more in the future. In fact, we believe that the autonomous systems of the future will greatly rely on autonomic properties for their viability, and their very existence.

We must be careful, however, not to make the mistakes that many other communities have made. That is, we must be conscious of the limitations of Autonomic Computing, and not make claims for it that we cannot substantiate. However, we must continue to pursue the 
field and ensure that its contributions are both developed further and applied in practice. We must demonstrate successes and the sustainability of the effort, without succumbing to the hyperboie that has stifled progress in other disciplines.

Right now it's only a notion but I think I can get money to make it into a concept and then later change it into an idea.

Woody Allen, "Annie Hall"

\section{Acknowledgements}

A great debt is due to EASe contributors, EASe program committee and TC-ECBS.

\section{References}

[1] A.G. Ganek, T.A. Corbi, "The dawning of the autonomic computing era", IBM Systems Journal, 42(1), 2003.

[2] H. Tianfield, Multi-agent based autonomic architecture for network management", Proceedings of INDIN 2003, IEEE International Conference on Industrial Informatics, 21-24 Aug. 2003, pp 462 469.

[3] R. Sterritt, "Autonomic Computing", Innovations in Systems and Software Engineering: a NASA Journal, Springer, 1(1), April 2005.

[4] C. Rouff, A. Vanderbilt, M. Hinchey, W. Truszkowski, J. Rash, "Verification of Emergent Behaviors in Swarm-based Systems", Proceedings of IEEE Workshop on the Engineering of Autonomic Systems (EASe 2004) at 11th Annual IEEE International Conference and Workshop on the Engineering of Computer Based Systems (ECBS 2004), Brno, Czech Republic, 24-27 May 2004, pp 443-448.

[5] R. Sterrith, D. Gunning, A. Meban, P. Henning, "Exploring Autonomic Options in an Unified Fault Management Architecture through Reflex Reactions via Pulse Monitoring", Proceedings of IEEE Workshop on the Engineering of Autonomic Systems (EASe 2004) at the 11th Annual IEEE International Conference and Workshop on the Engineering of Computer Based Systems (ECBS 2004), Brno, Czech Republic, 24-27 May 2004, pp 449-455.

[6] J. Nichols, T. Bapty, "A model-based self-adaptive approach to image processing", Proceedings of IEEE Workshop on the Engineering of Autonomic Systems (EASe 2004) at 11th Annual IEEE International Conference and Workshop on the Engineering of Computer Based Systems (ECBS 2004), Bmo, Czech Republic, 24-27 May 2004, pp 456-461.

[7] S. Shetty, S. Neema, T. Bapty, "Model Based Self Adaptive Behavior Language for Large Scale Realtime Systems", Proceedings of IEEE Workshop on the Engineering of Autonomic Systems (EASe 2004) at 11th Annual IEEE International Conference and Workshop on the Engineering of Computer Based Systems (ECBS 2004), Bmo, Czech Republic, 24-27 May 2004, pp $478-483$.

[8] W. Truszkowski, J. Rash, C. Rouff, M. Hinchey, "Asteroid Exploration with Autonomic Systems", Proceedings of IEEE Workshop on the Engineering of Autonomic Systems (EASe 2004) at 11th Annual IEEE International Conference and Workshop on the Engineering of Computer Based Systems (ECBS 2004), Bmo, Czech Republic, 24-27 May 2004, pp 484-489.

[9] W. Truszkowski, J. Rash, C. Rouff, M. Hinchey, "Some Autonomic Properties of Two Legacy MultiAgent Systems - LOGOS and ACT", Proceedings of IEEE Workshop on the Engineering of Autonomic Systems (EASe 2004) at 11th Annual IEEE International Conference and Workshop on the Engineering of Computer Based Systems (ECBS 2004), Bmo, Czech Republic, 24-27 May 2004, pp 490-498.

[10] D. Gracanin, S.A. Bohner, M. Hinchey, "Towards a Model-Driven Architecture for Autonomic Systems", Proceedings of IEEE Workshop on the Engineering of Autonomic Systems (EASe 2004) at 1lth Annual IEEE International Conference and Workshop on the Engineering of Computer Based Systems (ECBS 2004), Bmo, Czech Republic, 24-27 May 2004, pp 500-505.

[11] Y. Caseau, "Self-Adaptive and Self-Healing Message Passing Strategies for Process-Oriented Integration Infrastructures", Proceedings of IEEE Workshop on the Engineering of Autonomic Systems (EASe 2004) at 11th Annual IEEE International Conference and Workshop on the Engineering of Computer Based Systems (ECBS 2004), Brno, Czech Republic, 24-27 May 2004, pp 506-512.

[12] Sterritt R, Chung S, "Personal Autonomic Computing Self-Healing Tool", Proceedings of IEEE Workshop on the Engineering of Autonomic Systems (EASe 2004) at 11th Annual IEEE International Conference and Workshop on the Engineering of Computer Based Systems (ECBS 2004), Bmo, Czech Republic, 24-27 May 2004, pp 513-520.

[13] Y. Diao, J.L. Hellerstein, S. Parekh, G. Kaiser, D. Phung, "Self-Managing Systems: A Control Theory Foundation", Proceedings of IEEE Workshop on the Engineering of Autonomic Systems (EASe 2005) at 12th Annual IEEE International Conference and Workshop on the Engineering of Computer Based Systems (ECBS 2005), Greenbelt, MD, USA, 3-8 April, 2005, pp XXX-XXX.

[14] M. Randles, A. Taleb-Bendiab, P. Miseldine, A. Laws, "Adjustable Deliberation of Self-Managing Systems", Proceedings of IEEE Workshop on the Engineering of Autonomic Systems (EASe 2005) at 12th Annual IEEE International Conference and Workshop on the Engineering of Computer Based Systems (ECBS 2005), Greenbelt, MD, USA, 3-8 April, 2005, pp XXX-XXX. 
[15] Q. Wang, A. Mathur, "Interceptor based Constraint Violation Detection", Proceedings of IEEE Workshop on the Engineering of Autonomic Systems (EASe 2005) at 12th Aniwal IEEE International Conference and Workshop on the Engineering of Computer Based Systems (ECBS 2005), Greenbelt, MD, USA, 3-8 April, 2005, pp XXX-XXX.

[16] D. Bustard, R. Sterritt, A. Taleb-Bendiab, A. Laws, M. Randles, F. Keenan "Towards a Systemic Approach to Autonomic Systems Engineering", Proceedings of IEEE Workshop on the Engineering of Autonomic Systems (EASe 2005) at 12th Annual IEEE International Conference and Workshop on the Engineering of Computer Based Systems (ECBS 2005), Greenbelt, MD, USA, 3-8 April, 2005, pp XXX-XXX.

[17] G. Friedland, K. Pauls, "Towards a Demand Driven, Autonomous Processing and Streaming Architecture", Proceedings of IEEE Workshop on the Engineering of Autonomic Systems (EASe 2005) at 12th Annual IEEE International Conference and Workshop on the Engineering of Computer Based Systems (ECBS 2005), Greenbelt, MD, USA, 3-8 April, 2005, pp $\mathrm{XXX}-\mathrm{XXX}$.

[18] S. Shetty, S. Nordstrom, S. Ahuja, D. Yao, T. Bapty, S. Neema, "Systems Integration of Large Scale Autonomic Systems using Multiple Domain Specific Modeling Language", Proceedings of IEEE Workshop on the Engineering of Autonomic Systems (EASe 2005) at 12th Annual IEEE International Conference and Workshop on the Engineering of Computer Based Systems (ECBS 2005), Greenbelt, MD, USA, 3-8 April, 2005, pp XXX-XXX.

[19] J. Rash, M. Hinchey, C. Rouff, D. Gracanin, "Experiences with a Requirements-Based Programming Approach to the Development of a NASA Autonomous Ground Control System", Proceedings of IEEE Workshop on the Engineering of Autonomic Systems (EASe 2005) at 12th Annual IEEE International Conference and Workshop on the Engineering of Computer Based Systems (ECBS 2005), Greenbelt, MD, USA, 3-8 April, 2005, pp XXX-XXX.

[20] D. Messie, M. Jung, J. C. Oh, "Prototype of Fault Adaptive Embedded Software for Large-Scale RealTime Systems", Proceedings of IEEE Workshop on the Engineering of Autonomic Systems (EASe 2005) at 12th Annual IEEE International Conference and Workshop on the Engineering of Computer Based Systems (ECBS 2005), Greenbelt, MD, USA, 3-8 April, 2005, pp XXX-XXX.
[21] R. Sterritt, M.G. Hinchey, "Engineering Ultimate SelfProtection in Autonomic Agents for Space Exploration Missions", Proceedings of IEEE Workshop on the Engineering of Autonomic Systems (EASe 2005) at 12th Annual IEEE International Conference and Workshop on the Engineering of Computer Based Systems (ECBS 2005), Greenbelt, MD, USA, 3-8 April, 2005, pp XXX-XXX.

[22] R. Sterritt, "PACT: Personal Autonomic Computing Tools", Proceedings of IEEE Workshop on the Engineering of Autonomic Systems (EASe 2005) at 12th Annual IEEE International Conference and Workshop on the Engineering of Computer Based Systems (ECBS 2005), Greenbelt, MD, USA, 3-8 April, 2005, pp XXX-XXX.

[23] J. D. Baldassari, C. L. Kopec, E. S. Leshay, W. Truszkowski, D. Finkel, "Autonomic Cluster Management System (ACMS): A Demonstration of Autonomic Principles at Work", Proceedings of IEEE Workshop on the Engineering of Autonomic Systems (EASe 2005) at 12th Annual IEEE International Conference and Workshop on the Engineering of Computer Based Systems (ECBS 2005), Greenbelt, MD, USA, 3-8 April, 2005, pp XXX-XXX.

[24] F. Saffre, H. R. Blok "SelfService: Self-organised distribution of services for P2P communities", Proceedings of IEEE Workshop on the Engineering of Autonomic Systems (EASe 2005) at 12th Annual IEEE International Conference and Workshop on the Engineering of Computer Based Systems (ECBS 2005), Greenbelt, MD, USA, 3-8 April, 2005, pp XXX-XXX.

[25] J.P. Bowen and M.G. Hinchey, "“'Tis Greek to Me: Method in the Madness". In M.G. Hinchey and J.P. Bowen, editors, Industrial Strength Formal Methods in Practice, Springer Verlag FACIT series, London, 1999.

[26] M.G. Hinchey and J.P. Bowen, "Appiications of Formal Methods FAQ". In M.G. Hinchey and J.P. Bowen, editors, Applications of Formal Methods, Prentice Hall, Hemel Hempstead and Englewood Cliffs, 1995.

[27] J.P. Bowen and M.G. Hinchey, Seven More Myths of Formal Methods. IEEE Software, 12(4):34-41, July 1995.

[28] H.A. Simon, Models of My Life, Basic Books, NY, 1991.

[29] H.L. Dreyfus, What Computers Still Can't Do: A Critique of Artificial Reason, MIT Press, Cambridge, MA, 1992. 